University of Nebraska - Lincoln

DigitalCommons@University of Nebraska - Lincoln

Faculty Publications, Department of Child, Youth, and Family Studies

Child, Youth, and Family Studies, Department of

July 1991

\title{
Moral versus Social-Conventional Reasoning: A Narrative and Cultural Critique
}

Carol S. Witherell

Lewis \& Clark College

Carolyn P. Edwards

University of Nebraska-Lincoln, cedwards1@unl.edu

Follow this and additional works at: https://digitalcommons.unl.edu/famconfacpub

Part of the Family, Life Course, and Society Commons

Witherell, Carol S. and Edwards, Carolyn P., "Moral versus Social-Conventional Reasoning: A Narrative and Cultural Critique" (1991). Faculty Publications, Department of Child, Youth, and Family Studies. 5. https://digitalcommons.unl.edu/famconfacpub/5

This Article is brought to you for free and open access by the Child, Youth, and Family Studies, Department of at DigitalCommons@University of Nebraska - Lincoln. It has been accepted for inclusion in Faculty Publications, Department of Child, Youth, and Family Studies by an authorized administrator of DigitalCommons@University of Nebraska - Lincoln. 


\section{Moral versus Social-Conventional Reasoning: A Narrative and Cultural Critique*}

\author{
Carol S. Witherell, Lewis \& Clark College
}

\author{
Carolyn Pope Edwards, University of Kentucky [University of \\ Nebraska-Lincoln]
}

\begin{abstract}
We suggest in this paper that attempts to segregate social-conventional reasoning from the moral domain may represent an artifactual division, one that ignores major philosophic and psychological traditions and cultural constructs regarding the moral self. We address such issues as the individual, social, and relational dimensions of morality; the cultural context of moral development and behavior; and whether morality is solely a matter of justice, harm and welfare considerations, or concerned as well with culturally variable definitions of the good and the good society, with role obligations, and with caring and affective aspects of human experience. We conclude with a call for continuing narrative and anthropological approaches to the study of moral development in order to reach a fuller understanding of the multiple facets of moral life.
\end{abstract}

\section{Introduction}

In his literary biography of Elie Wiesel, Robert McAfee Brown (1983) refers to the quandary faced by readers of Camus' The Artist Within as an appropriate metaphor for Wiesel's journal

* Published in Journal of Moral Education 20:3 (1991), pp 293-305. Copyright (C) 1991 Carfax Publishing Company. Used by permission. from his first book Night to his later novel Gates of the Forest. The quandary referred to in Camus' story is the reader's uncertainty as to whether a word written in very small print at the center of the artist's canvas is to be read as solitary or solidary. With the writing of Night, Wiesel broke 10 years of silence following his experience as a Holocaust victim. It is a story of his entry into the world of radical evil, and terror of the Nazi death camps and the despair and loss that followed-loss of faith, of trust, of self It is a story of ultimate isolation and solitariness. Five books later, in Gates of the Forest, Wiesel tells the story of Gregor, a young Hungarian Jew hiding from the Nazis. Gregor consents to a fellow refugee's offer to sacrifice himself in his place. He assumes a different identity, posing as a deaf-mute. His journey from this point on is one of coming to understand his own guilt, the world's suffering, and something of the moral quest. A story of restoration and reconciliation unfolds as Gregor reclaims his Jewish culture, faith and identity, and his ability to love. Gregor (and perhaps also Wiesel) recovers his sense of connection - to others and to life itself. His is a journey of goodness and response overcoming fear and silence. His moral identity and attachment to the world are reestablished through his experiences of solidarity and caring.

We begin our paper with this story from Elie Wiesel's life and work to illustrate that moral meanings conveyed in human stories have intricate cultural as well as personal contexts. Because of these contexts, no single psychological theory such as the cognitive-developmental approach is sufficient to explain the complexity of the moral realm. In this paper we will bring together a number of perspectives to support this claim and to suggest that recent attempts to segregate socialconventional reasoning from moral reasoning ignore important philosophic, psychological and anthropological perspectives in 
the study of the moral realm. Such a division, we will suggest, serves to restrict rather than expand our conceptual lens in the study of moral and ethical development.

\section{The Cognitive-Developmental Tradition}

Theories of morality have always engendered both controversy and mystique. Much of the controversy, as well as the mystique, has had to do with attempts to define what one means by the term 'moral'. Among the most prominent contributions to understanding morality from a psychological perspective is the work carried out by Lawrence Kohlberg and his colleagues and successors. Kohlberg viewed the core of morality as justice, although in one of his last works he identified beneficence as also central to the higher reaches of the moral domain (Kohlberg, 1984; Kohlberg et al. 1985).

In an attempt to further clarify the domain of morality from a psychological perspective, Elliot Turiel and others have conducted extensive research on the development of individuals' concepts of social conventions and moral issues. (See Nucci \& Turiel, 1978; Smetana, 1981, 1983; Nucci, 1982, 1986; Turiel, 1983; Turiel, et al., 1987). Each of these researchers has also participated in studies in non-Western societies to substantiate their claim that moral and conventional orientations are culturally universal (Nucci et al., 1983; Hollis et al., 1986; Sang et al., 1987).

From the standpoint of Turiel's framework, we can define the two domains under discussion as follows. Moral prescriptions are mandatory obligations-universally applicable and impartial (hence, not based on individual or cultural contexts). They are determined by criteria other than agreement, consensus, or institutional rule (Turiel, 1983; Turiel et al., 1987). Moral prescriptions center on issues of justice, harm and welfare; prototypical examples are proscriptions against stealing, hurting and promise-breaking. These norms are hypothesized to be constructed by children, at a very early age, on the basis of social interactions that allow children to notice the intrinsically harmful consequences of moral transgression.

By contrast, social conventions are defined as rules or expectations that do not derive their force from the intrinsic consequences of the acts to which they apply, but rather from their contextual meaning and their function as part of a particular social system. Outside of that system they are arbitrary; they become non-arbitrary to people in the system because they serve important social functions of communication, coordination and efficiency. Social conventions are relative or rule-contingent in that they derive their force from social consensus, agreement, or institutional rule. Examples of prototypical conventions would be rules of etiquette and school rules regulating children's movement, use of materials, modes of dress, and correct forms of addressing authority figures (e.g. teachers). The distinction between convention and morality is hypothesized to be constructed by children of pre-school ages, although the distinction is believed to be less stable and generalized at younger than at older ages. The understanding of social conventions is said to be the result of experiences that help children understand the social system of which they are a part. Such interactions might be ones that highlight authority, status and role relationships, the effects of order or disorder, contextual boundaries or rules, and the consequences of reward and punishment. Recent studies conducted by Nucci (1986) offer another example. Nucci has found that adolescents and young adults draw a distinction between 'moral issues' such as killing, rape, and slander, and 'non-moral issues' such 
as divorce, use of contraceptives, and pre-marital sex between consenting adults.

One of the central criticisms of the cognitive-developmental approach to morality is that moral considerations are restricted to justice considerations. By limiting the definition of morality to impartial and universalizable considerations of fairness, harm and welfare, Turiel's construction of morality is vulnerable to the central criticisms of deontological and non-consequentialist ethical theories. These criticisms include a lack of attention to: (1) the role of personal responsibilities and care that arise out of our commitments to particular others (Blum, 1982; Gilligan, 1982; Noddings, 1984, 1989, 1991; and Wong, $1984)$; (2) the role of altruism and supererogation in moral decision and action (Blum, 1980, Oliner \& Oliner, 1988; Kohn, 1990); and (3) the salience of cultural and contextual features in moral considerations and conduct (Shweder, 1982; Nisan, 1984, 1987; Edwards, 1985, 1987).

\section{Ethics of Care and Relativity}

While the notion that care, altruism, virtue and conceptions of the good have a central place in moral considerations is not new, our understanding of these dimensions of morality has been enhanced by the recent work of psychologists and ethicists such as Lawrence Blum (1982), Carol Gilligan (1982), Philip Hallie (1979), Alfie Kohn (1990), Jane Martin (1987), Iris Murdoch (1971), Alasdair MacIntyre (1981), Nel Noddings (1984; 1989; 1991), R. S. Peters (1972) and Joan Miller (in press).

Blum, Murdoch and Noddings note the absence of considerations of the ethical ideal or of moral paragons in contemporary ethical and moral theories. Blum, Gilligan, Noddings and Peters describe the relational and altruistic dimensions of moral experience. Blum describes acts of beneficence that arise from altruistic feelings involving "an internal connection with the good of the particular other person who is their object" (1984, p. 16). Gilligan and Noddings describe concerns individuals express regarding the impact of their actions and decisions on their relationships with particular individuals. In Caring, Noddings (1984) describes two feelings required for morality to be an "active virtue": the sentiment of natural caring (following Hume) and the memory of caring and being cared for, which leads to a feeling of the necessity to respond. Within Noddings' relational ethics, ethical caring is a response to the other summoned by an empathic feeling - the 'I must' that is drawn from our memories of caring and being cared for. Through this response the relation between persons is affirmed and maintained, and serves as an ideal in guiding moral choice. R. S. Peters (1972) speaks of the "unity of the moral life" in which reason, in pursuit of the good, is joined with concern and love for particular others.

These considerations of caring and concern for relationships are not necessarily in conflict with justice considerations. However, we do not consider them to be subsumed by justice considerations, as Kohlberg's moral stages suggest. Nor do they seem to be non-moral or secondarily moral considerations, as Turiel has claimed. We view caring as an essential partner to justice in an adequate theory of morality.

Nucci (1986) has concluded from his interviews that divorce and the use of contraception are examples of nonmoral actions akin to matters of social conventions, in contrast to actions of moral import such as killing, stealing, slander and rape. These delineations were based on adolescent and young adult subjects' judgments of transgressions - their seriousness, their prescriptivity, and their universality. This conclusion offers a poignant example of the restrictiveness of a moral the- 
ory that is essentially contract- and justice-bound. Few individuals who have experienced divorce or the failure of contraception would deny the moral dimensions of these events, for they include considerations of caring, justice, harm, promisekeeping, responsibility, welfare and the prospect of life itself. To classify such actions in the non-moral realm seems to us nonsensical. Such an example illustrates the vulnerability of a moral theory that holds that the morality of an act is evaluated solely on considerations of justice, welfare and harm.

We would not deny the cultural relativity of moral prescriptions that Nucci found in his interviews. But to make the claim that the domain of culturally variable rules is distinct from a supposedly universal moral domain is to obscure the rich cultural context of moral behavior and thought found by researchers from other traditions.

Wong, in Moral Relativity (1984), describes morality as a process of social creation born of the activity of reconciling "conflicts between rules and standards that arise within and between persons". His theory of 'limited relativity' allows for both universal and non-universal moral considerations that combine to regulate conflicts within a "particular community of language users". Wong describes his notion of a moral principle in the context of certain truth conditions.

A moral principle can have universal scope; that is, it can apply to all moral agents in the sense of directing them to perform certain actions; and it may be true of all agents given a certain set of truth conditions that a group or society assigns to the principle; but since there may be more than one set of truth conditions for the principle, it may not be universally justifiable to all agents. (1984, p. 188)

We should remark here that we have found it useful in discussions with our college students to distinguish between the notions of moral relativity and moral relativism, drawing from some of Wong's formulations.

Nisan (1984, 1987) has suggested that the distinction between morals and conventions evolves from a specific cultural orientation which founds morality in principles of welfare and justice, and that other contrasting orientations also exist. From his studies of 6-7 and 10-11 year-old children in four cultural groups in Israel (religious, non-religious, kibbutz Jewish children and Muslim children), Nisan concluded that at least some moral norms or rules perceived by children are culture-dependent. Using Turiel's distinction of 'morally wrong' vs. 'conventionally wrong' based on whether they felt there should be a law forbidding an action, Nisan found numerous examples where what was considered morally wrong by one group was considered only conventionally wrong by another. Among the examples Nisan offers: Muslim and religious Jewish children considered the bathing of boys and girls together a serious sin (independent of law), but this was not at all the view of kibbutz children. Because of these findings Nisan remains interested in the variety and types of moral norms that exist across cultures, including their cultural, environmental, and structural dimensions. The evaluation and judgments offered by the traditional Arab children he studied appeared to be based on a normative orientation to morality quite different from the welfare and justice orientation offered by the Jewish children.

What Wong, Nisan and Shweder have in common with MacIntyre is their acknowledgement of the importance of culture and community in conceptions of human flourishing, which in turn influence our notions of what is right, just, caring, responsible and virtuous. 
We would suggest that much of what have been construed as non-moral social or interpersonal conventions are indeed facets of moral life, although their 'bindingness' on us may vary significantly from those actions defined by Turiel as moral. Precisely because these actions are interpersonally and culturally variable processes, they are not amenable to categorization within a moral framework that limits the definition of morality to the products of individual cognitive operations. Edward Sampson $(1981,1989)$ has referred to this practice as a dual reduction - that of individualism and subjectivism; more broadly, he questions the routine adoption of empirical-analytic science as "our implicit framework for understanding human life and behavior" (1981, p. 741).

\section{Methodological Concerns}

From a psychological perspective, we would raise concerns about the empirical basis for the claim that concepts of morality necessarily form a system of value-knowledge distinct from concepts of convention.

Our concerns do not have to do with the rigor or reliability of the work that has been carried out in this area. Turiel, Nucci, Smetana, Rillen and their associates are careful researchers who explain their procedures and results fully and encourage outside researchers to replicate their work. Their findings suggest to us that when schoolchildren are asked certain kinds of questions about certain kinds of transgressions, their answers are predictable and indeed reveal differences between kinds of transgressions. However, we are not convinced that the results prove that morality and convention necessarily represent two distinct domains of value knowledge. The observed differences might just as easily indicate that child's rule-knowledge includes early awareness of criteria for distinguishing the 'bindingness' of rules, without saying anything about their separation of moral and conventional domains.

In describing the research paradigm used in this work, we will focus on the studies of children's social concepts as assessed by interviews, although similar commentary could be made about the studies involving social interaction. The typical study presents children with a small set of moral and conventional transgression situations, about each of which they are asked a standard set of probing questions. The transgressions are presented in the form of verbal vignettes or pictures, depending on the age of the children. The 'moral' transgressions used in the studies come from a limited set of interpersonal acts of aggression or unfairness that virtually all children agree are 'very bad'. For example, Smetana's (1981) study of pre-school children involved five moral stimulus items: hitting, not sharing a toy; shoving; throwing water at another child; and taking another child's apple. The 'conventional' transgressions also come from a limited set-typically violations of schools procedures, rules of etiquette, and dress codes that seem (to use, at least) to be rather trivial, that is, they do not involve consequences that would be considered very undesirable by the children.

Smetana (1981) used the following transgressions: not participating in classroom 'show and tell,' not sitting in the designated place (a rug) during story time; not saying grace before snack; not putting a toy away in the correct spot; and not putting one's personal belongings in the designated place. The probing questions following the transgressions typically involve some or all of the following questions: how bad each transgression is; why it is wrong; whether the act would be wrong even if there were no rule about it (rule-contingency); 
whether the act might be all right in some other place (rulerelativity); and whether the act should be punished.

We need to ask here whether the limited nature of the stimulus items 'pulls for' the results obtained. First, the researchers may have weakened the interpretability of their findings by selecting moral and conventional items that are most contrasting in terms of the proposed underlying dimensions (that is, intrinsic versus arbitrary, universal versus context-bound, etc.), thus making it likely that they would get strong results suggestive of dichotomous domains. The studies have not seriously tested Rest's (1983) hypothesis that there is one socio-moral continuum rather than two domains. It should be noted that Turiel, Nucci and Smetana do not postulate that every event is purely moral or purely conventional, but instead acknowledge fuzzy boundaries and blended events. However, they do postulate that there are enough pure events to cause children to construct a conceptually sharp moral-conventional conventional distinction. To validate the integrity of different domains more research is needed in such areas as younger children's understanding of 'conventional' transgressions that might seem to them serious and non-rule-contingent. Examples of these dilemmas might be: going about naked in public, wiping one's nose on one's clothes, throwing food on a clean rug, dumping all of the toys off the classroom shelves. We might speculate that these would be considered serious transgressions to young children not because of rule or justice concerns, but because of concerns regarding the degree of offence or harm to others' feelings, hence, relational concerns. Noddings suggests in Caring (1984) and Women and Evil (1989) that relational concerns are at the heart of the moral realm.

Second, by discussing findings primarily in terms of group means in subjects' responses, the researchers direct our atten- tion away from the often substantial individual differences in the implicit categorization of items. For example, Arsenio \& Ford (1985) report that the following percentages of first to third grade children (aged 6-9) said that it would not be all right' to commit the following infractions if there were no rule: moral items: stealing another child's toys, $81 \%$ hitting another child without provocation, $81 \%$; breaking a glass and falsely blaming a classmate, $77 \%$; conventional items eating spaghetti with one's fingers, $54 \%$; not lining up outside the classroom as required, 54\%; deliberately using the wrong gender bathroom, $50 \%$. These aggregated results, comparable with other studies, are indeed impressive and interesting; yet they indicate that about half of the time, the children responded to 'conventional' items in a 'moral' way, and about $20 \%$ of the time, they responded to 'moral' items in a 'conventional' way. What do such results mean? Do children differ from one another in which items they consider 'moral,' which 'conventional'? Do some children consistently not distinguish 'moral' and 'conventional'? Either way, what do the individual differences indicate about the hypothesis of domains of value knowledge?

In fact, some evidence already exists to support the idea that 'convention' represents not a distinct domain of ruleknowledge but rather a kind of second order thinking about morality that emerges in certain conditions and/or certain cultures. Siegal \& Storey (1985), studying Australian children in day-care settings, found that newly enrolled children differentiate 'moral' and 'conventional' transgressions much less sharply than do day-care veterans; the authors suggest that daycare experience heightens children's awareness of differences between rules. Edwards $(1985,1987)$ analyzed a corpus of 105 naturally occurring moral events observed among Luo children in the South Nyanza district of Kenya. The data offer 
no support for Turiel, Nucci and Smetana's claim that justice, harm and welfare episodes elicit qualitatively different kinds of reactions from adults than episodes concerning task assignment and proper social behavior. They do not appear to be embedded in qualitatively different kinds of social interactions. Finally, Shweder et al., (1987) studied children and adults from Chicago, USA, and Bhubaneswar, North India. Because their procedures were different, their findings that Indians engaged in much less relativistic thinking than Americans, and American children much less than American adults, are not directly comparable to those of Turiel, Nucci, Smetana, Killen and colleagues. Nevertheless, their ethnographic comparison of American and Indian thinking about morality and conclusions about the mandatory vs. discretionary features of a moral code are important.

Shweder et al., (1987) put these claims in cultural perspective by arguing that several discretionary features underlie both Kohlberg's and Turiel and his colleagues' understandings of moral (and conventional) reasoning (1) an 'individualism' that conceives of the individual as prior to society and conceptually abstracted from all particular qualities; (2) Western definitions of 'moral agent' and 'territories of the self, that bound who and what is entitled to moral consideration and protection from harm; and (3) decisions regarding which kinds of invasions to particular aspects of the self are to be considered harmful. These definitions, Shweder et al. (1987) argue, are what give rise to Turiel's Westernized notions of why violations of sexual codes count not as moral transgressions but rather as mere social conventional violations.

The Latin word 'mores,' from which the word 'morals' is derived, means 'custom,' and in many parts of the world, including orthodox Hindu India, customary practices (for example, menstrual seclusion, arranged marriage, food taboos, kin avoidance, naming practices) are viewed as part of the natural-moral order. Society is not separated conceptually from nature. What is natural or moral has not been narrowed down to the idea of an individual, empowered and free to create relationships at will through contract. Forms of human association are thought to be found (natural law), not founded (conventionism). In those parts of the world, the idea that social practices are conventions plays a minimal role in the child's developing understanding of the source of obligations. (p. 4)

In this view, then, the particular communities and contexts of which a person is a part are not just attributes that one possesses, but are constituents of one's personhood, one's identity.

\section{Conceptions of the Person and the Moral Self}

A further psychological consideration is that of the conception of the person implicit in the worn of Turiel et al. The equation of the epistemological subject with the person is a practice common to all cognitive-developmental theories. The focus on the development of cognitive operations grounded in perspective-taking, equilibration and logical operations assumes a self that, while interactive with its environment, is constituted reflexively in relation to itself (its mental processes) prior to its relation to other selves. This conception of the autonomous self, a legacy of Kant and Descartes, has been challenged by Gilligan and Noddings from the standpoint of an alternative conception of 'persons-in-relation' and by Sampson (1981; 1989); Shweder (1982); and Shweder, et al., (1987) from the standpoint of persons as socially constituted beings.

Noddings (1984) describes the ethical self as "an active relation". The ethical self is grounded in receptivity and relat- 
edness. In contrast to traditional individualistic ethical systems where the focus is on duty or principle, the relational ethic proposed by Noddings considers the feelings and response of the other and the health of the relation between persons as primary. The health of the relation pertains both to the relation between self and other and to the relation between the actual self and the 'best self' - itself a relational entity. For Noddings, the self is a network of social and potential relations, and not an isolated bounded entity.

It is not just that I as a preformed continuous individual enter into relations; rather, the I of which we speak so easily is itself a relational entity. I really am defined by the set of relations into which my physical self has been thrown. (1989, p. 237)

Noddings' notions of the self-in-relation and relational ethics suggest a much different approach to educating children than that practiced in most classrooms and cultures within the United States and Europe. The ideology of individualism and competitive achievement that is at the core of these educational systems may inhibit the development of children's capacity for moral understanding that embraces both caring and justice concerns. Noddings (1984; 1989) and Martin (1987) have each urged educators to consider transforming schools and classrooms into places where human caring is at the center, as a legacy for the future as well as an achievement for the present. Noddings describes such an ethic at work in a classroom:

The teacher who encourages receptivity wants the child to look, to listen, to touch, and, perhaps, to receive a vision of reality. When we speak of receiving reality, we do not deny that each human consciousness participates in the construction of reality, but we give proper emphasis to the relatedness that must be perceived and accepted before any coherent picture can be constructed. The other is received, his reality is apprehended as possibility for oneself.

Alasdair MacIntyre, in After Virtue (1981), describes the essential link between the moral life and notions of the good, identified within a community of seekers of shared goods. He seeks to restore to our consciousness the importance of stories, as they provide the fabric of 'the narrative unity of the human life,' a narrative grounded in cultural, historical and biographical identity. MacIntyre associates the abandonment of stories with our contemporary relegation of art to a 'minority activity':

The contrast, indeed the opposition, between art and

life ... provides a way of exempting art-including narrative-from its moral tasks. And the relegation of art by modernity to the status of an essentially minority activity and interest further helps to protect us from any narrative understanding- of ourselves ... To think of a human life as a narrative unity is to think in a way alien to the dominant individualist and bureaucratic modes of modern culture. (p. 211)

\section{Conclusion}

When we consider these perspectives, we find support for a dialectical, philosophically grounded model of development that recognizes the interrelation between individual, interpersonal, social and cultural schemes, a model considerably broader than the individual constructivism of the cognitivedevelopmental tradition. From our interests in anthropology, ethics and narrative psychology, we would argue abundant uses of ethnography and interviewing methods that draw upon the power of story and metaphor in human action and dialogue. While the alterability, prescriptivity, and universality of rules expressed by individuals confronting hypothetical 
dilemmas provide important and interesting understandings of one dimension of morality, we have suggested that other significant dimensions of moral development remain untapped through the structured interviewing method used in many studies of moral development. We would recommend a deeper probing of issues that subjects themselves identify as moral problems, and, as well, the inclusion of subjects from a wide range of cultural and experiential backgrounds. This could help us understand the ways that individuals are guided by their cultural experiences to rediscover and construct certain values and ideas that are part of their cultural traditions. Mark Tappan \& Lyn Mikel Brown's (1991) recent work in narrative and hermeneutics, building on methodological advances begun by Carol Gilligan (1982) and her associates, exemplifies a genre of growing significance in moral development research.

We would also recommend a greater attention to particular social, cultural and linguistic contexts in methods such as interviewing, psychobiography and thematic analyses of autobiographical and fictional writing. Such attention should reveal the intricate tapestries of individual, cultural and biographical narratives as they shape moral life, enriching our understanding of the nature, scope and interconnections of moral considerations in our lives.

\section{References}

ARSENIO, W.F. \& FORD, M.E. (1985) The role of affective information in social-cognitive development: children's differentiation of moral and conventional events, Merrill Palmer Quarterly, 31, pp. $1-17$

BLUM, L.A. (1980) Friendship, Altruism, and Morality (London, Routledge \& Kegan Paul).
BROWN, R. McAFEE (1983) Elie Wiesel: messenger to all Humanity (Notre Dame, IN, University of Notre Dame Press).

EDWARDS, C.P. (1985) Another style of competence: the caregiving child, in: A. D. FOGEL \& G. F. NELSON (Eds.) Origins of Nurturance, pp. 95-122 (New York, Erlbaum).

EDWARDS, C.P. (1987) Culture and the construction of moral values: a comparative ethnography of moral encounters in two cultural settings, in: J. KAGAN \& S. LAMB (Eds.) The Origins of Morality in Young Children, pp. 123-150 (Chicago, University of Chicago Press).

GILLIGAN, C. (1982) In A Different Voice: psychological theory and women's development (Cambridge, MA, Harvard University Press).

HALLIE, P. (1979) Lest Innocent Blood be Shed (New York, Harper \& Row).

HOLLIS, MAVIDA, LEIS, PHILIP, E. \& TURIEL, E. (1986) Social reasoning in Ijo children and adolescents in Nigeria communities, Journal of Cross-Cultural Psychology, 17, pp. 352-374.

KOHLBERG, L. (1984) Essays on Moral Development Vol. 2: the psychology of moral development (San Francisco, CA, Harper \& Row).

KOHLBERG, L., BOYD, D. \& LEVINE, $C$. (1985) The return of stage 6: its principle and moral point of view, in: W. EDELSTEIN \& G. UNNER-WINKLER (Eds.) Proceedings of the Second Ringberg Conference.

KOHN, A. (1990) The Brighter Side of Human Nature: altruism and empathy in everyday life (New York, Basic Books).

MACINTYRE, A. (1981) After Virtue (Notre Dame, IN, University of Notre Dame Press).

MARTIN, J. (1987) Transforming moral education, Journal of Moral Education, 16, pp. 204-213. 
MILLER, J. (in press) A cultural perspective on the morality of beneficence and interpersonal responsibility, in: S. TING-TOOMEY \& F KORZENNY (Eds.) Cross cultural Interpersonal Communication Vol. 15 (Newbury Park, CA, Sage Publications).

MURDOCH, I. (1971) The Sovereignty of Good (New York, Shocken).

NISAN, M. (1984) Content and structure in moral judgment: an integrative view, in: W. M. KURTINES \& J. L. GEWIRTZ, Morality, Moral Behavior, and Moral Development, pp. 208-224 (New York, John Wiley \& Sons).

NISAN, M. (1987) Moral norms and social conventions: a cross-cultural comparison, Developmental Psychology, 23, pp. 719-725.

NODDINGS, N. (1984) Caring: a feminine approach to ethics and moral education (Berkeley, CA, University of California Press).

NODDINGS, N. (1989) Women and Evil (Berkeley, CA, University of California Press).

NODDINGS, N. (1991) Stories in Dialogue: caring and interpersonal reasoning, in: $\boldsymbol{C}$. WITHERELL \& N. NODDINGS (Ed) Stories Lives Tell: narrative and dialogue in education (New York, Teachers College Press).

NUCCI, L.P. (1982) Conceptual development in the moral and conventional domains: implications for values education, Review of Educational Research, 52, pp. 93-122.

NUCCI, L.P. (1986) Children's conceptions of morality social conventions, and religious prescriptions, in: $C$. HARDING (Ed.) Moral Dilemmas: philosophical and psychological reconsiderations of the development of moral reasoning (Chicago, Precedent Press).

NUCCI, L.P. \& TURIEL, E. (1978) Social interactions and the development of social concepts in preschool children, Child Development, 49, pp. 400-407

NUCCI, L.P., TURIEL, E. \& ENCARNACION-GAWRYCH' G. (1983) Children's social interactions and social concepts: analysis of morality and convention in the Virgin Islands, Journal of CrossCultural Psychology, 14, pp. 469-487.

OLINER, S.P. \& OLINER, P.M. (1988) The altruistic personality (New York, Free Press).

PETERS, R.S. (1972) Reason and Compassion (Lectures from the Lindsay Memorial Lectures and the Swarthmore Lecture) (London, Routledge \& Kegan Paul).

REST, J. (1983) Morality, in: J. H. FLAVELL \& E. MARKMAN (Eds.) Handbook of Child Psychology: Vol. 3. cognitive development, 4th edn., pp. 261-360 (New York, Wiley).

SAMPSON, E.E. (1981) Cognitive psychology as ideology, American Psychologist, 36, pp. 730-743.

SAMPSON, E.E. (1989) The challenge of social change for psychology: globalization and psychology's theory of the person, American Psychologist, 44, pp. 914-921.

SHWEDER, R.A. (1982) Beyond self-constructed knowledge: the study of culture and morality, Merrill Palmer Quarterly, 28, pp. 41-69.

SHWEDER, R.A., MAHAPATRA, M. \& MILLER, J.A. (1987) Culture and moral development in India and the United States, in: J. KAGAN \& S. LAMB (Eds) Emergence of Morality in Young Children, pp. 1-82 (Chicago, University of Chicago Press).

SIEGAL, M. \& STOREY, RM. (1985) Day care and children's conceptions of moral and social rules, Chad Development, 56, pp. 10011008.

SMETANA, J. (1981) Pre-school children's conceptions of moral and social rules, Child Development, 52, pp. 1333-1336.

SMETANA, J. (1983) Social-cognitive development: domain distinctions and coordinations, Developmental Review, 3, pp. 131-147. 
SONG, M.-P., SMETANA, J.G. \& KIM, S.Y. (1987) Korean children's conceptions of moral and conventional transgressions, Developmental Psychology, 23, pp. 577-582.

TAPPAN, M. \& BROWN, L.M. (1991) Stories told and lessons learned: toward a narrative approach to moral development and moral education, in: $\mathcal{C}$. WITHERELL \& N. NODDINGS (Eds.) Stories Lives Tell: narrative and dialogue in education (New York, Teachers College Press).

TURIEL, E. (1983) The Development of Social Knowledge: morality and convention (New York, Cambridge University Press).

TURIEL, E., KILLEN, M. \& HELWIG, C.C. (1987) Morality: its structure, functions, and vagaries, in: J. KAGAN \& S. LAMB (Eds.) The emergence of Morality in Young Children, pp. 155-244 (Chicago: University of Chicago Press).

WIESEL, E. (1982) Night (New York, Bantam Books) (Original work published in 1958).

WIESEL, E. (1982) Gates of the Forest, Trans. Frances Frenaye (New York, Schocken Books) (Original work published in 1964).

WONG, D.B. (1984) Moral Relativity (Berkeley, CA, University of California Press). 